\title{
Coronavirus Pandemic
}

\section{Spontaneous pneumothorax, with or without pulmonary cysts, in patients with COVID-19 pneumonia}

\author{
Javier Leonardo Galindo¹, Luisa Fernanda Jiménez², Juan Ricardo Lutz¹, María Alejandra Izquierdo", \\ Viviana Lucía Rivillas², Jorge Alberto Carrillo 3 \\ ${ }^{1}$ Department of Pneumology, Hospital Universitario Mayor Méderi - Universidad del Rosario. Bogotá, D.C., \\ Colombia \\ ${ }^{2}$ Department of Internal Medicine, Hospital Universitario Mayor Méderi - Universidad del Rosario. Bogotá, D.C., \\ Colombia \\ ${ }^{3}$ Department of Radiology, Hospital Universitario Mayor Méderi - Universidad del Rosario. Bogotá, D.C., Colombia
}

\begin{abstract}
Introduction: Severe Acute Respiratory Syndrome Coronavirus 2 (SARS-CoV-2) affects mainly the lungs causing pneumonia and complications like acute respiratory distress syndrome. Pneumothorax is a rare manifestation of the disease. This report is a description of a series of patients with COVID-19 and spontaneous pneumothorax, some of them with associated pulmonary cysts.

Methodology: Cases were collected retrospectively. We included clinical data from medical records and described radiologic findings. Patients that developed pneumothorax during mechanical ventilation were excluded.

Results: Ten cases were included in this report, nine of them were male. The median age of our series was 62 years $(\mathrm{IQR}=57-68)$. The median days since the onset of symptoms until the development of pneumothorax was 27 (IQR $=17-31)$, most cases developed after the second week of the diagnosis of pneumonia. Two cases required invasive mechanical ventilation, but pneumothorax occurred after ventilator weaning. Three cases showed subpleural pulmonary cysts.

Conclusions: Cysts and pneumothorax are rare manifestations of SARS-CoV-2 pneumonia with mechanisms not completely understood. This report highlights the role of CT scan in diagnosis of COVID-19 complications.
\end{abstract}

Key words: Viral pneumonia; COVID-19; pneumothorax; cysts.

J Infect Dev Ctries 2021; 15(10):1404-1407. doi:10.3855/jidc.15054

(Received 18 March 2021 - Accepted 18 June 2021)

Copyright (C) 2021 Galindo et al. This is an open-access article distributed under the Creative Commons Attribution License, which permits unrestricted use, distribution, and reproduction in any medium, provided the original work is properly cited.

\section{Introduction}

Coronavirus disease 2019 (COVID-19) has become a health emergency worldwide causing pneumonia as its main manifestation. The most common chest computed tomography (CT) features are consolidations, ground-glass opacities, or both, with predominantly bilateral, basal, and peripheral distribution [1]. Spontaneous pneumothorax and pulmonary cystic spaces have been reported as a rare complication of COVID-19. The aim of this report is to describe cases of patients from a single-center with COVID-19 pneumonia and spontaneous pneumothorax, not related to mechanical ventilation, in some cases associated with pulmonary cysts.

\section{Cases report}

We collected retrospectively ten laboratoryconfirmed COVID-19 patients that developed spontaneous pneumothorax. Patients that developed pneumothorax during mechanical ventilation were excluded.

The median age of patients was 62 years $(\mathrm{IQR}=57$ 68), nine of them were male. In all cases pneumothorax was suspected because symptoms and oxygenation acutely worsened, nine cases presented chest pain. The median days since the onset of symptoms until the development of pneumothorax was 27 (IQR = 17-31), only two patients developed this complication in the first two weeks. There were two cases with pneumothorax at the time of admission to the emergency department, one case developed pneumothorax during their inpatient admission, and seven cases developed this complication after being discharged from the first admission for COVID-19. Two cases required invasive mechanical ventilation, but pneumothoraces occurred after ventilator weaning.

Only one patient had chronic obstructive pulmonary disease (COPD) as previous chronic lung disease. One 
patient had a history of HIV. No patient had thoracic trauma associated with pneumothorax.

The right side was affected in three cases, the left side in four, and three had bilateral pneumothorax. Chest X-ray failed to identify the pneumothoraces in three cases because they were loculated. Patients underwent chest $\mathrm{CT}$ scanning that showed multilobe subpleural consolidations or ground-glass opacities once COVID-19 was diagnosed. Three cases with CT scan follow-up showed evidence of subpleural thinwalled cystic spaces development associated with pneumothorax (Figure 1). Chest CT did not suggest pulmonary infarction or parenchymal cavitation in any case; CT pulmonary angiography was performed in six cases ruling out pulmonary embolism.

All patients required supplemental oxygen therapy; pneumothorax did not require drainage in one patient. Only one case died of respiratory failure due to COVID19. No tissue samples were collected for pathology.

\section{Ethics approval and consent to participate}

Written informed consents were taken from the patients for publication of these cases and any accompanying images. This report was approved by the Medical Ethic Committee of Rosario University.

\section{Discussion}

We have described a case series of COVID-19 patients with pneumothorax, some related to cystic lesions. This series remarks the role of CT scan in diagnosis and identification of COVID-19 complications and the importance of clinical suspicion of pneumothorax as a potentially life-threatening complication in patients with acute worsening of symptoms. In three cases, follow-up chest CT demonstrated cysts development associated with pneumothorax, indicating its temporal relationship with COVID-19. Most of the patients did not have any risk factors for cysts or pneumothorax development, including smoking, underlying chronic lung diseases, trauma, or use of positive-pressure ventilation. Infectious diseases, such as necrotizing pneumonia and Pneumocystis jirovecii pneumonia, may cause air-filled spaces that sometimes lead to secondary pneumothorax. We do believe that lung damage caused by COVID-19 explains the development of these findings, and it is

Figure 1. Clinical presentation COVID-19 cases with evidence of pulmonary cysts development.
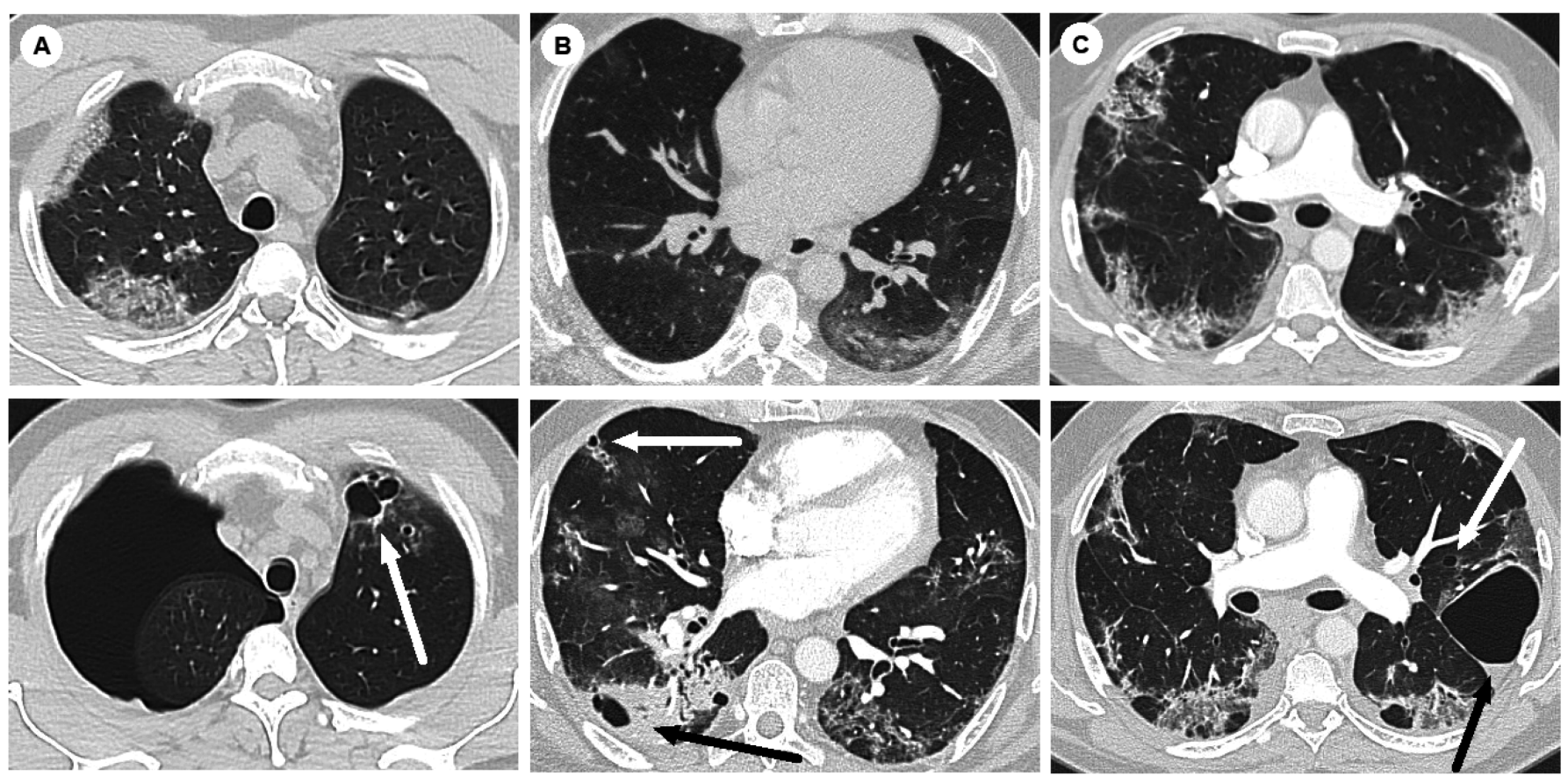

A: A 39-year-old man with a 12-day history of fever, dyspnea, cough, sore throat, vomit, and diarrhea; high-resolution CT showed multifocal upper lobe consolidations (top panel). 29 days later CT scan showed left upper lobe subpleural cystic lesions (white arrow) associated with ground-glass opacities and right pneumothorax (bottom panel). B: A 58-year-old with a 5-day history of fever, cough, dyspnea, and diarrhea; high-resolution CT showed multilobar ground-glass peripheral opacities (top panel). He required invasive mechanical ventilation for ten days. 31 days later CT scan showed multilobar groundglass opacities, consolidations, parenchymal bands and loculated right pneumothorax (black arrow); middle lobe and right lower lobe had subpleural cysts (white arrow) (bottom panel). C: A 63-year-old man was admitted presenting with an 8-day history of cough, fever, asthenia, headache, and dyspnea; highresolution CT showed multilobar ground-glass opacities (top panel). CT scan obtained 48 days later showed left upper lobe cystic spaces (white arrow), associated with ground-glass opacities and loculated left pneumothorax (black arrow) (bottom panel). 
possible that cysts formation may play a role in the pathophysiology of pneumothorax.

The most common patterns of COVID-19 pneumonia on CT scans are ground-glass opacities (88.0\%), with peripheral (76.0\%) and bilateral (87.5\%) distribution, and multilobe involvement (78.8\%) [1]. Bronchiectasis, nodules, septal thickening, pleural effusion, and lymphadenopathy are less common and found at a later stage of the disease. Cystic spaces have been reported in up to $10 \%$ and spontaneous pneumothorax in $1 \%$ of SARS-CoV-2 pneumonia cases $[2,3]$.

Pneumothorax has been reported predominantly in male patients, in some cases as an early presentation of COVID-19 and in other cases as a late complication after two weeks of symptom onset, the latter sometimes associated with pulmonary cysts (Table 1) [4,13]. Cysts linked to pneumothorax in COVID-19 have been described in few case reports. Liu et al. [9] described a series of two men with pneumothorax and peripheral pulmonary cysts after 26 and 40 days of symptom onset; cysts decreased in number and size in the followup of both cases.

A multicenter case series in the UK described sixty pneumothoraces and six pneumothoraces with pneumomediastinum in patients who developed this complication at admission or during hospitalization, regardless of the use of positive-pressure ventilation [14]. The incidence of pneumothorax was higher in males (3.3:1) and did not affect COVID-19 prognosis. In one case, CT scan showed subpleural cysts correlated to the pathology finding of a cystic space transitioning with respiratory epithelium.

The pathogenesis of pulmonary cysts in COVID-19 is not well understood. Proposed mechanisms of cystic lung disease include necrosis due to ischemia, remodeling of interstitial matrix, and bronchial obstruction with distal hyperinflation phenomenon due to a check-valve mechanism. Histopathologic features of COVID-19 may help to understand the mechanism of pneumothorax and cystic lesions; reports of autopsies have showed lung injury consistent with early acute respiratory distress syndrome as the main finding, followed by acute fibrinous and organizing pneumonia, microthrombi, vascular congestion and necrosis with microvascular damage [6,15]. Ischemia due to microvascular damage and exudates causing a checkvalve mechanism within airspaces could be involved in cysts formation [9]. However, the late development of cysts suggests that alveolar wall destruction is more likely related to the healing process in areas of

Table 1. Summary of characteristics of some COVID-19 series reported with pneumothorax associated to cysts or bullae.

\begin{tabular}{|c|c|c|c|c|c|c|c|}
\hline Reference & $\begin{array}{l}\text { Age, } \\
\text { years }\end{array}$ & Sex & $\begin{array}{l}\text { Days from illness onset } \\
\text { to pneumothorax }\end{array}$ & $\begin{array}{c}\text { Smoking } \\
\text { history }\end{array}$ & $\begin{array}{c}\text { Chronic lung } \\
\text { disease }\end{array}$ & $\begin{array}{c}\text { Mechanical } \\
\text { ventilation }\end{array}$ & $\begin{array}{c}\text { Lung cysts or } \\
\text { bullae }\end{array}$ \\
\hline \multirow[t]{2}{*}{ Aiolfi A, et al. [4] } & 56 & Male & $\mathrm{N} / \mathrm{A}$ & Yes & No & Yes & Yes \\
\hline & 70 & Male & $\mathrm{N} / \mathrm{A}$ & No & No & Yes & Yes \\
\hline \multirow[t]{3}{*}{ Al-Shokri, et al. [5] } & 55 & Male & 10 & N/A & No & Yes & No \\
\hline & 33 & Male & 20 & N/A & No & Yes & Yes \\
\hline & 50 & Male & $\mathrm{N} / \mathrm{A}$ & N/A & No & No & $\mathrm{N} / \mathrm{A}$ \\
\hline \multirow{2}{*}{ Bellini B, et al. [6] } & 58 & Male & $\mathrm{N} / \mathrm{A}$ & Yes & No & No & No \\
\hline & 53 & Female & 3 & No & No & No & Yes \\
\hline Capleton P, et al. [7] & 64 & Female & N/A & No & Bronchiectasis & Yes & Yes \\
\hline Flower L, et al. [8] & 36 & Male & 21 & Yes & Asthma & No & Yes \\
\hline \multirow[t]{2}{*}{ Liu K, et al. [9] } & 38 & Male & 26 & N/A & No & No & Yes \\
\hline & 35 & Male & 40 & N/A & No & Yes & Yes \\
\hline \multirow{3}{*}{ Mallick T, et al. [10] } & 40 & Male & 7 & Yes & No & No & Yes \\
\hline & 68 & Male & 23 & No & No & No & Yes \\
\hline & 58 & Female & N/A & No & No & No & No \\
\hline Sanivarapu RR, et al. [11] & 40 & Male & 17 & No & No & No & Yes \\
\hline Sun $\mathrm{R}$, et al. [12] & 38 & Male & 39 & N/A & No & Yes & Yes \\
\hline Yasukawa K, et al. [13] & 37 & Male & 30 & $\mathrm{~N} / \mathrm{A}$ & No & No & Yes \\
\hline \multirow[t]{10}{*}{ Present study } & 39 & Male & 29 & Yes & No & No & Yes \\
\hline & 58 & Male & 31 & No & No & Yes & Yes \\
\hline & 71 & Male & 7 & No & No & No & No \\
\hline & 62 & Male & 30 & Yes & COPD & No & Yes \\
\hline & 56 & Male & 15 & No & No & No & No \\
\hline & 54 & Male & 25 & No & No & No & No \\
\hline & 79 & Male & 12 & No & No & No & No \\
\hline & 69 & Male & 21 & No & No & No & No \\
\hline & 64 & Male & 42 & Yes & No & No & Yes \\
\hline & 62 & Female & 42 & No & No & No & Yes \\
\hline
\end{tabular}


resorption of consolidation than to the early inflammatory damage [7].

\section{Conclusions}

There are few reports of cases to date of pneumothorax and cysts in COVID-19 to date. Mechanisms of these complications in patients with COVID-19 are not yet completely understood; further information from histopathological observations may help to elucidate them.

\section{Acknowledgements}

We thank our colleagues from Hospital Universitario Mayor Méderi and Centro de Investigaciones Méderi (CIMED), especially Luisa Murcia who assisted in the manuscript preparation.

\section{Author contributions}

All authors have read and approved the manuscript. JLG. LFJ: Methodology, Investigation, Writing - Review and Editing. JRL, MAI and VLR: Investigation, Writing Original Draft. JAC: Conceptualization.

\section{References}

1. Salehi S, Abedi A, Balakrishnan S, Gholamrezanezhad A (2020) Coronavirus disease 2019 (COVID-19): a systematic review of imaging findings in 919 patients. AJR Am J Roentgenol 215: 87-93.

2. Shi H, Han X, Jiang N, Cao Y, Alwalid O, Gu J, Fan Y, Zheng C (2020) Radiological findings from 81 patients with COVID19 pneumonia in Wuhan, China: a descriptive study. Lancet Infect Dis 20: 425-434.

3. Chen N, Zhou M, Dong X, Qu J, Gong F, Han Y, Qiu Y, Wang J, Liu Y, Wei Y, Xia J, Yu T, Zhang X, Zhang L (2020) Epidemiological and clinical characteristics of 99 cases of 2019 novel coronavirus pneumonia in Wuhan, China: a descriptive study. Lancet 395: 507-513.

4. Aiolfi A, Biraghi T, Montisci A, Bonitta G, Micheletto G, Donatelli F, Cirri S, Bona D (2020) Management of persistent pneumothorax with thoracoscopy and bleb resection in COVID-19 patients. Ann Thorac Surg 110: e413-e415.

5. Al-Shokri SD, Ahmed AOE, Saleh AO, AbouKamar M, Ahmed K, Mohamed MFH (2020) Case report: COVID-19related pneumothorax-case series highlighting a significant complication. Am J Trop Med Hyg 103: 1166-1169.
6. Bellini R, Salandini MC, Cuttin S, Mauro S, Scarpazza P, Cotsoglou C (2020) Spontaneous pneumothorax as unusual presenting symptom of COVID-19 pneumonia: surgical management and pathological findings. J Cardiothorac Surg 15: 310 .

7. Capleton P, Ricketts W, Lau K, Ellis S, Sheaff M, Giaslakiotis K, Uys S, Tchrakian N (2021) Pneumothorax and pneumatocoele formation in a patient with COVID-19: a case report. SN Compr Clin Med: 1-4. [Online ahead of print]

8. Flower L, Carter J-PL, Rosales Lopez J, Henry AM (2020) Tension pneumothorax in a patient with COVID-19. BMJ Case Rep 13: e235861.

9. Liu K, Zeng Y, Xie P, Ye X, Xu G, Liu J, Wang H, Qian J (2020) COVID-19 with cystic features on computed tomography: a case report. Medicine (Baltimore) 99: e20175.

10. Mallick T, Dinesh A, Engdahl R, Sabado M (2020) COVID-19 complicated by spontaneous pneumothorax. Cureus 12: e9104.

11. Sanivarapu RR, Farraj K, Sayedy N, Anjum F (2020) Rapidly developing large pneumatocele and spontaneous pneumothorax in SARS-CoV-2 infection. Respir Med Case Rep 31: 101303.

12. Sun R, Liu H, Wang X (2020) Mediastinal emphysema, giant bulla, and pneumothorax developed during the course of COVID-19 pneumonia. Korean J Radiol 21: 541-544.

13. Yasukawa K, Vamadevan A, Rollins R (2020) Bulla formation and tension pneumothorax in a patient with COVID-19. Am J Trop Med Hyg 103: 943-944.

14. Martinelli AW, Ingle T, Newman J, Nadeem I, Jackson K, Lane ND, Melhorn J, Davies HE, Rostron AJ, Adeni A, Conroy K, Woznitza N, Matson M, Brill SE, Murray J, Shah A, Naran R, Hare SS, Collas O, Bigham S, Spiro M, Huang MM, Iqbal B, Trenfield S, Ledot S, Desai S, Standing L, Babar J, Mahroof R, Smith I, Lee K, Tchrakian N, Uys S, Ricketts W, Patel ARC, Aujayeb A, Kokosi M, Wilkinson AJK, Marciniak SJ (2020) COVID-19 and pneumothorax: a multicentre retrospective case series. Eur Respir J 56: 2002697.

15. Polak SB, Van Gool IC, Cohen D, von der Thüsen JH, van Paassen J (2020) A systematic review of pathological findings in COVID-19: a pathophysiological timeline and possible mechanisms of disease progression. Mod Pathol 33: 21282138 .

\section{Corresponding author}

Dr. Javier Leonardo Galindo, MD.

Department of Pneumology, Hospital Universitario Mayor Méderi. Calle 24 \# 29-45. Bogotá, Colombia.

Phone: +57 3174333190

Email: zafiro.urgencias@mederi.com.co

Conflict of interests: No conflict of interests is declared. 